\title{
Enhanced hardness in epitaxial TiAlScN alloy thin films and rocksalt TiN/(Al,Sc)N superlattices
}

\author{
Bivas Saha, Samantha K. Lawrence, Jeremy Schroeder, Jens Birch, David F. Bahr and \\ Timothy D. Sands
}

\section{Linköping University Post Print}

\section{Tweet}

N.B.: When citing this work, cite the original article.

Original Publication:

Bivas Saha, Samantha K. Lawrence, Jeremy Schroeder, Jens Birch, David F. Bahr and Timothy D. Sands, Enhanced hardness in epitaxial TiAlScN alloy thin films and rocksalt TiN/(Al,Sc)N superlattices, 2014, Applied Physics Letters, (105), 15, 151904.

http://dx.doi.org/10.1063/1.4898067

Copyright: American Institute of Physics (AIP) http://www.aip.org/

Postprint available at: Linköping University Electronic Press http://urn.kb.se/resolve?urn=urn:nbn:se:liu:diva-112480 


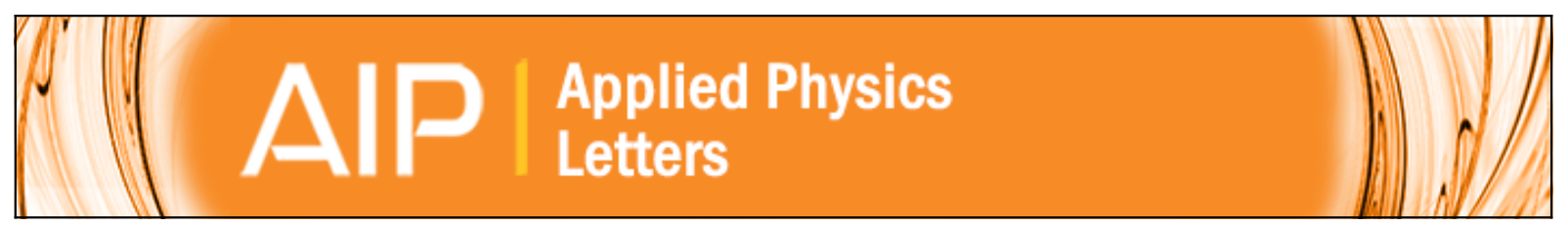

\section{Enhanced hardness in epitaxial TiAIScN alloy thin films and rocksalt TiN/(AI,Sc)N}

\section{superlattices}

Bivas Saha, Samantha K. Lawrence, Jeremy L. Schroeder, Jens Birch, David F. Bahr, and Timothy D. Sands

Citation: Applied Physics Letters 105, 151904 (2014); doi: 10.1063/1.4898067

View online: http://dx.doi.org/10.1063/1.4898067

View Table of Contents: http://scitation.aip.org/content/aip/journal/apl/105/15?ver=pdfcov

Published by the AIP Publishing

\section{Articles you may be interested in}

Microstructure and dielectric properties of piezoelectric magnetron sputtered w-ScxAl1-xN thin films

J. Appl. Phys. 111, 093527 (2012); 10.1063/1.4714220

Topotaxial growth of Ti 2 Al N by solid state reaction in Al N/Ti ( 0001 ) multilayer thin films

Appl. Phys. Lett. 90, 174106 (2007); 10.1063/1.2731520

Deposition of Ti 2 Al C and Ti 3 Al C 2 epitaxial films by magnetron sputtering

Appl. Phys. Lett. 85, 1066 (2004); 10.1063/1.1780597

Enhanced stability of rocksalt-type AIN phase in AIN/TiN superlattices synthesized by room-temperature pulsed laser deposition

J. Appl. Phys. 92, 4255 (2002); 10.1063/1.1506398

Synthesis and characterization of highly textured polycrystalline AIN/TiN superlattice coatings

J. Vac. Sci. Technol. A 16, 3341 (1998); 10.1116/1.581542

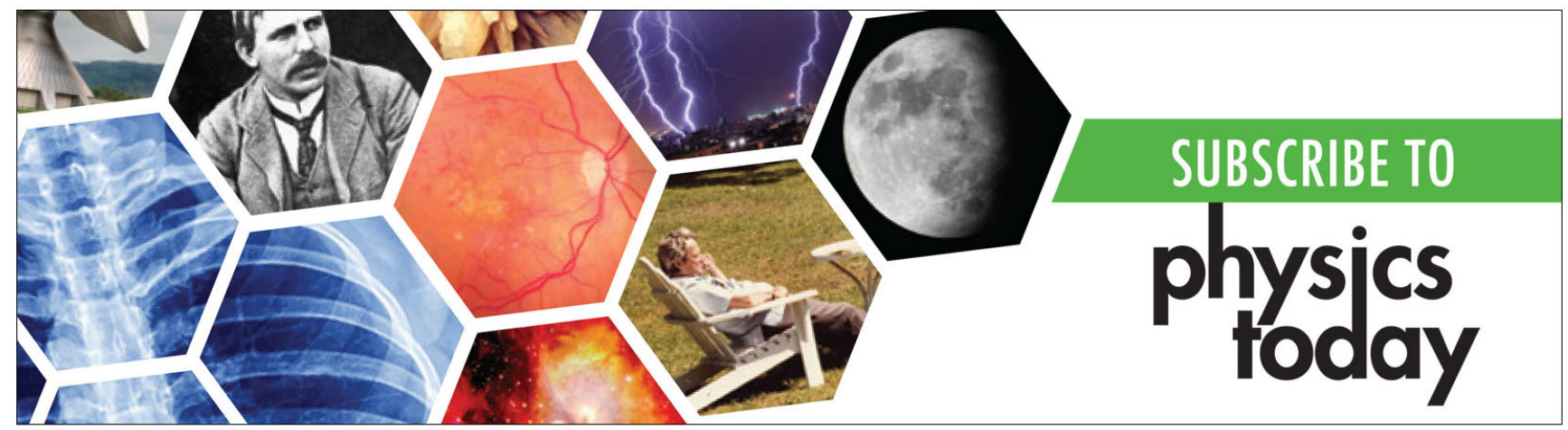




\title{
Enhanced hardness in epitaxial TiAIScN alloy thin films and rocksalt $\mathrm{TiN} /(\mathbf{A l}, \mathrm{Sc}) \mathrm{N}$ superlattices
}

\author{
Bivas Saha, ${ }^{1,2}$ Samantha K. Lawrence, ${ }^{1}$ Jeremy L. Schroeder, ${ }^{3}$ Jens Birch, ${ }^{3}$ David F. Bahr, ${ }^{1}$ \\ and Timothy D. Sands ${ }^{1,2,4}$ \\ ${ }^{1}$ School of Materials Engineering, Purdue University, West Lafayette, Indiana 47907, USA \\ ${ }^{2}$ Birck Nanotechnology Center, Purdue University, West Lafayette, Indiana 47907, USA \\ ${ }^{3}$ Thin Film Physics Division, Department of Physics, Chemistry, and Biology (IFM), Linköping University, \\ SE-581 83 Linköping, Sweden \\ ${ }^{4}$ School of Electrical and Computer Engineering, Purdue University, West Lafayette, Indiana 47907, USA
}

(Received 19 August 2014; accepted 2 October 2014; published online 14 October 2014)

\begin{abstract}
High hardness TiAlN alloys for wear-resistant coatings exhibit limited lifetimes at elevated temperatures due to a cubic-AIN to hexagonal-AlN phase transformation that leads to decreasing hardness. We enhance the hardness (up to $46 \mathrm{GPa}$ ) and maximum operating temperature (up to $1050{ }^{\circ} \mathrm{C}$ ) of TiAlN-based coatings by alloying with scandium nitride to form both an epitaxial TiAlScN alloy film and epitaxial rocksalt TiN/(Al,Sc)N superlattices on $\mathrm{MgO}$ substrates. The superlattice hardness increases with decreasing period thickness, which is understood by the Orowan bowing mechanism of the confined layer slip model. These results make them worthy of additional research for industrial coating applications. (C) 2014 AIP Publishing LLC. [http://dx.doi.org/10.1063/1.4898067]
\end{abstract}

Hardness is a measure of how readily dislocations are formed within a material and how easily these dislocations propagate under an applied stress. Hardness is directly associated with a material's plastic properties, and is only indirectly associated with its elastic constants. ${ }^{1,2}$ Researchers have often wondered whether it is possible to design a material with a hardness approaching or greater than that of diamond (the hardest known material). The design and realization of superhard materials would prove beneficial in abrasion/wear-resistant applications like cutting tools, bearings, and tribology. ${ }^{3-6}$

Transition metal nitrides are attractive as coating materials in many technological applications ${ }^{7,8}$ since they are hard, chemically stable at high temperatures, exhibit high melting temperatures, and are readily deposited on tooling substrates via both reactive sputtering and cathodic arc deposition. Titanium nitride (TiN) is a leading coating material ${ }^{9,10}$ which is used for edge retention and corrosion resistance on machine tooling, such as drill bits and milling cutters, often improving tool lifetime by a factor of three or more. However, the hardness of TiN is relatively low $(\approx 20-24 \mathrm{GPa})$ and the oxidation resistance of $\mathrm{TiN}$ in air is limited to temperatures below $700{ }^{\circ} \mathrm{C}$, beyond which $\mathrm{TiN}$ forms $\mathrm{TiO}_{2}$ and nitrogen bubbles. ${ }^{11}$ Several ternary and quaternary alloy systems of TiN (e.g., (Ti,Al)N, (Ti,C)N, and $(\mathrm{Ti}, \mathrm{Al}, \mathrm{V}) \mathrm{N})$ have been developed to increase hardness and oxidation resistance. (Ti,Al)Nbased coatings ${ }^{12}$ are the most commonly employed industrial tool coating with hardness greater than that of TiN and exhibiting greater oxidation resistant than TiN. Despite its superior properties, $(\mathrm{Ti}, \mathrm{Al}) \mathrm{N}$-based coatings have a limited maximum operating temperature and lifetime due to the formation of hexagonal AlN grains at high temperatures. ${ }^{13}$

Thin-film multilayers and superlattices are a potential configuration that may realize extraordinarily hard materials with long lifetime at high operating temperatures. Koehler ${ }^{14}$ proposed in the 1970s that the interfaces in superlattices should act as high energy barriers for dislocation motion, thereby increasing hardness. Based on their suggestion, several superlattice systems ${ }^{15-17}$ (e.g., TiN/NbN, TiN/VN, and $\mathrm{TiN} / \mathrm{CrN}$ ) have been developed that show improved hardness compared to TiN and (Ti,Al)N. However, all of the nitride superlattices mentioned above are miscible at temperatures exceeding $800^{\circ} \mathrm{C}$, which significantly limits their usefulness in cutting tool applications where the surface temperature can reach as high as $1000^{\circ} \mathrm{C}$ during the cutting process. Cubic (rocksalt)-TiN/AlN superlattices have been developed ${ }^{18}$ to overcome the miscibility problem since TiN/ AlN superlattices are immiscible up to $\sim 1000{ }^{\circ} \mathrm{C} .{ }^{19} \mathrm{TiN} /$ AlN superlattices also exhibit excellent oxidation resistance, relatively high hardness compared to $\mathrm{TiN}$, and they are already used commercially as a coating material.

However, TiN/AlN superlattice coatings have a significant drawback that limits their practical applications. The hardness of TiN/AlN superlattices is around 33-35 GPa when the thickness of the AlN layers is less than $2-3 \mathrm{~nm}$, but decreases sharply to $23-24 \mathrm{GPa}$ as the AlN layer thickness is increased. This large reduction in hardness is attributed to the transition from the epitaxially stabilized metastable c-AlN phase to the stable wurtzite-AlN phase when the AlN layer thickness exceeds the critical thickness of $2-3 \mathrm{~nm} .{ }^{18,20,21}$ The formation of wurtzite-AlN breaks the epitaxial relationship with c-TiN leading to polycrystalline grain growth and a significant hardness reduction. The same c-AlN to wurtzite-AlN transition is also the cause for deteriorating hardness in industrial TiAlN tool coatings.

We overcome the significant critical thickness limitation of TiN/AlN superlattices by alloying the AlN layers with scandium nitride $(\mathrm{ScN})$. We previously reported on epitaxially stabilized c- $(\mathrm{Al}, \mathrm{Sc}) \mathrm{N}$ films deposited on TiN/MgO substrates with critical thickness values exceeding $200 \mathrm{~nm} .{ }^{22}$ The resulting c-TiN/(Al,Sc)N superlattices exhibit enhanced hardness values compared to traditional TiAlN coatings and are stable at higher temperatures (up to $4 \mathrm{~h}$ at $1050^{\circ} \mathrm{C}$ ). The confined layer slip model is used to explain the hardness enhancement in the superlattices. Surprisingly, a $\mathrm{Ti}_{0.5} \mathrm{Al}_{0.36} \mathrm{Sc}_{0.14} \mathrm{~N}$ alloy 
thin film, whose composition represents the average composition of the $\mathrm{TiN} / \mathrm{Al}_{0.72} \mathrm{Sc}_{0.28} \mathrm{~N}$ superlattices studied herein, exhibits the highest hardness value ( $46 \mathrm{GPa}$ ) of all our films, even exceeding the hardness of the superlattice films. The alloy result is promising given the simplicity of deposition and high temperature stability afforded to alloy films versus superlattices.

In addition to $\mathrm{MgO}(001)$ substrates, alloy and superlattice films were also deposited on $\mathrm{Si}(001)$ and sapphire (0001) substrates. Microstructural characteristics and mechanical properties of these films are presented in the supplementary material ${ }^{35}$ with the remainder of the paper focused on films deposited on $\mathrm{MgO}$.

In order to deposit single-crystalline defect-free TiN/ $(\mathrm{Al}, \mathrm{Sc}) \mathrm{N}$ superlattices, the $(\mathrm{Al}, \mathrm{Sc}) \mathrm{N}$ alloy was lattice matched with TiN using 72\% AlN mole fraction. The TiN/ $\mathrm{Al}_{0.72} \mathrm{Sc}_{0.28} \mathrm{~N}$ superlattices discussed herein are single crystalline and coherent. The crystallographic and microstructural characteristics of the TiN/ $\mathrm{Al}_{0.72} \mathrm{Sc}_{0.28} \mathrm{~N}$ superlattices are briefly described and the mechanical properties are discussed in greater detail to show the usefulness of TiN/ $(\mathrm{Al}, \mathrm{Sc}) \mathrm{N}$ superlattices as well as $\mathrm{Ti}_{0.5} \mathrm{Al}_{0.36} \mathrm{Sc}_{0.14} \mathrm{~N}$ alloys as hard-coating materials. The individual thin film and the superlattices are deposited with a reactive dc-magnetron sputtering technique inside a high vacuum chamber. Details of the superlattice growth, x-ray diffraction, and TEM analysis are presented in the experimental details section of the supplementary material. ${ }^{35}$

The x-ray diffraction spectra of TiN/ $\mathrm{Al}_{0.72} \mathrm{Sc}_{0.28} \mathrm{~N}$ superlattices (Fig. 1(a)) show that the superlattices grow with a 002-orientation on $\mathrm{MgO}$ (001) substrates. The superlattices exhibit a small degree of mosaicity indicated by an extremely small rocking curve full-width-at-half-maximum (FWHM) of $0.065^{\circ}$ for the 002 diffraction peak. Such a small rocking curve FWHM value suggests that the superlattices are nearly single crystalline. A reciprocal space $x$-ray map from the $10 \mathrm{~nm} / 10 \mathrm{~nm} \quad \mathrm{TiN} / \mathrm{Al}_{0.72} \mathrm{Sc}_{0.28} \mathrm{~N}$ superlattice (Fig. 1(b) adapted from our previous publication (Ref. 23)) suggests that the superlattices are pseudomorphic on $\mathrm{MgO}$ (001) substrates. The 024 superlattice diffraction peak, the $024 \mathrm{MgO}$ diffraction peak, and the interference fringes are all aligned vertically indicating that the in-plane lattice constants of both $\mathrm{TiN}$ and $\mathrm{Al}_{0.72} \mathrm{Sc}_{0.28} \mathrm{~N}$ are fixed with that of $\mathrm{MgO}(4.21 \AA)$. The out-of-plane lattice constants for TiN and $\mathrm{Al}_{0.72} \mathrm{Sc}_{0.28} \mathrm{~N}$ are $4.23 \AA$ and $4.26 \AA$, respectively. The interference fringes in both Figs. 1(a) and 1(b) are distinct and sharp, indicating atomically abrupt interfaces. X-ray reflectivity (XRR) measurements (not presented here, see Ref. 24 for detailed analysis) and subsequent data fitting suggest that the interface roughness values are on the order of $0.2-0.4 \mathrm{~nm}$, which corresponds to one to two atomic layers.

The $\mathrm{Ti}_{0.5} \mathrm{Al}_{0.36} \mathrm{Sc}_{0.14} \mathrm{~N}$ alloy thin film (lattice constant $=4.24 \AA$ ) also grows with a 002-orientation on $\mathrm{MgO}$ (001) substrates as shown in the symmetric $2 \theta-\omega$ x-ray diffraction spectrum of Figure 1(c). The rocking curve FWHM of the 002 diffraction peak is about $0.04^{\circ}$, indicating that the alloy is nominally single crystalline, and exhibits improved crystal quality compared to the superlattices.

The thermal stability of the superlattices were investigated via ex-situ annealing treatments in forming gas $(5 \%$ $\mathrm{H}_{2}: 95 \% \mathrm{~N}_{2}$ ) followed by synchrotron based x-ray diffraction with a 2D-detector. A detailed treatment of the annealing study is beyond the scope of this article and will be presented in a separate report. However, we have observed that the TiN/ $\mathrm{Al}_{0.72} \mathrm{Sc}_{0.28} \mathrm{~N}$ superlattices are stable at $1050^{\circ} \mathrm{C}$ for $4 \mathrm{~h}$. As the annealing time is increased, the metastable $\mathrm{Al}_{0.72} \mathrm{Sc}_{0.28} \mathrm{~N}$
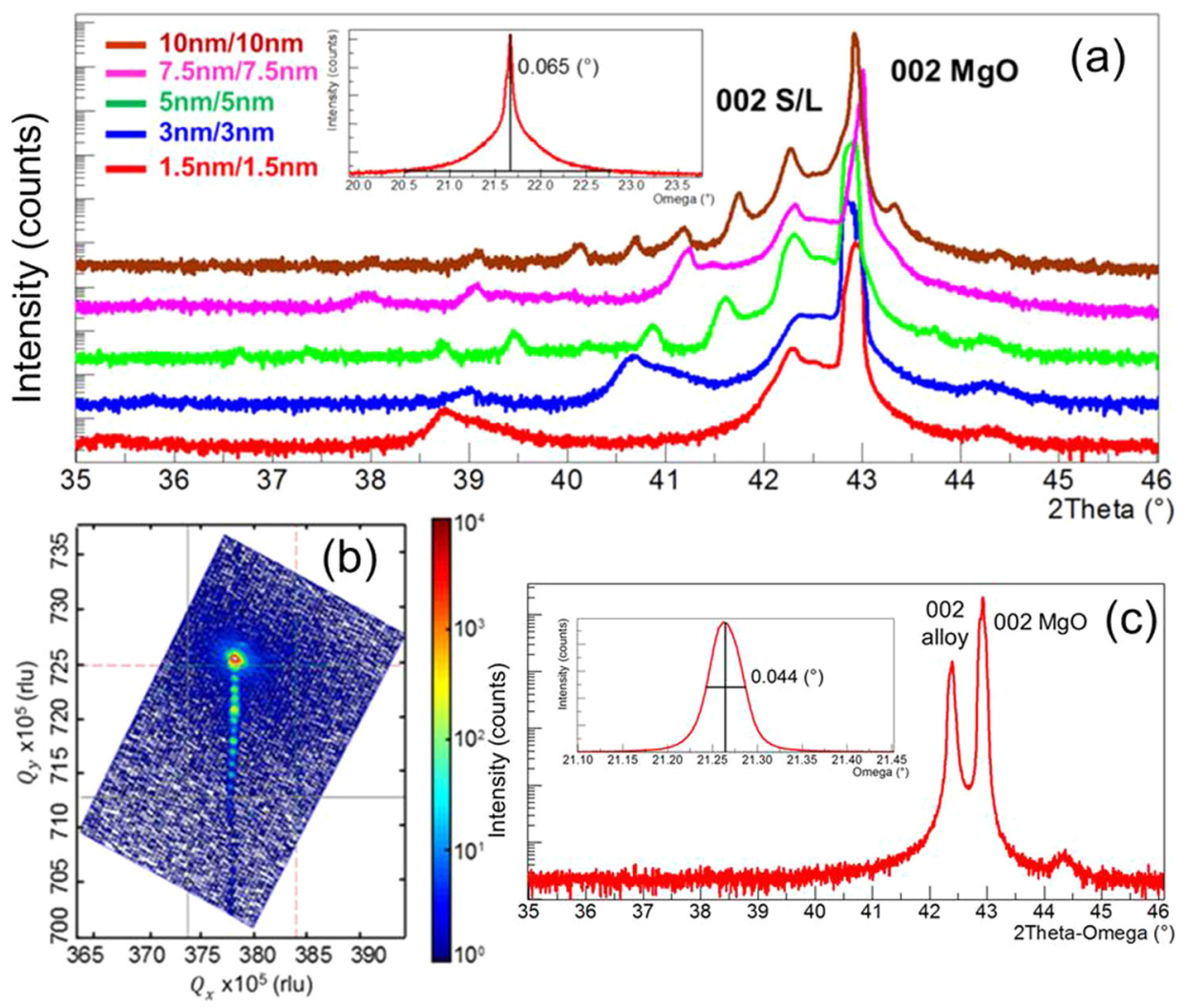

FIG. 1. (a) Symmetric $2 \theta-\omega x$-ray diffraction spectra of the TiN/Al $\mathrm{Al}_{0.72} \mathrm{Sc}_{0.28} \mathrm{~N}$ superlattices as a function of superlattice period. The superlattices grow with 002-orientation on the $\mathrm{MgO}$ (001) substrates with small a degree of mosaicity. (b) Reciprocal space $x$-ray 024 diffraction map of the $10 \mathrm{~nm} / 10 \mathrm{~nm}$ superlattice suggesting the pseudomorphic and epitaxial nature of superlattices when deposited on $\mathrm{MgO}$ (001) substrates. (c) Symmetric $2 \theta-\omega x$-ray diffraction spectrum of the $\mathrm{Ti}_{0.5} \mathrm{Al}_{0.36} \mathrm{Sc}_{0.14} \mathrm{~N}$ alloy thin film deposited on an $\mathrm{MgO}$ (001) substrate. The smaller rocking curve FWHM value for the alloy thin film compared to the superlattice films indicates higher crystal quality in the alloy thin film (Adapted from Ref. 23). 
undergoes a rocksalt to wurtzite structural phase transformation that is captured in our synchrotron analysis.

The microstructures of the superlattices are characterized by high resolution transmission electron microscopy (HRTEM) and high angle annular dark field scanning transmission electron microscopy (HAADF-STEM) based techniques. The HRTEM image in Fig. 2(a) shows a high quality $\mathrm{TiN} / \mathrm{Al}_{0.72} \mathrm{Sc}_{0.28} \mathrm{~N}$ superlattice with sharp interfaces where the TiN layer thickness is kept constant at $20 \mathrm{~nm}$ and the $\mathrm{Al}_{0.72} \mathrm{Sc}_{0.28} \mathrm{~N}$ layer thickness is varied from $2 \mathrm{~nm}$ to $80 \mathrm{~nm}$. Even the $2 \mathrm{~nm} \mathrm{Al}_{0.72} \mathrm{Sc}_{0.28} \mathrm{~N}$ layer is clearly visible in Fig. 2(a). The high magnification image of the TiN/Al ${ }_{0.72} \mathrm{Sc}_{0.28} \mathrm{~N}$ interface (Fig. 2(b)) shows a cube-on-cube epitaxial relationship of TiN (001)[100]||MgO (001)[100] and $\mathrm{Al}_{0.72} \mathrm{Sc}_{0.28} \mathrm{~N}$ (001)[100]||TiN (001)[100]. The interfaces are latticematched and pseudomorphic. We do not see any signature of a misfit dislocation at the interface as far as we can verify. The fast Fourier transformation (FFT) from the $\mathrm{Al}_{0.72} \mathrm{Sc}_{0.28} \mathrm{~N}$ region indicates a rocksalt (cubic) diffraction pattern, which demonstrates the stabilization of the metastable rocksalt phase of $\mathrm{Al}_{0.72} \mathrm{Sc}_{0.28} \mathrm{~N}$ between TiN layers. An HAADFSTEM image (Fig. 2(c)) shows TiN layers (light layers) and $\mathrm{Al}_{0.72} \mathrm{Sc}_{0.28} \mathrm{~N}$ layers (dark layers) along with some $\mathrm{V}$-shaped structural defects that originate at the substrate surface and propagate through the superlattice.

The mechanical properties of the superlattices and individual reference thin films were measured via nanoindentation with a Hysitron Triboindenter 950 equipped with a Berkovich probe with a radius of approximately $150 \mathrm{~nm}$. Forty-nine indents, arrayed in a square, were made in each sample using a load controlled, partial-unloading method with a peak load of $2000 \mu \mathrm{N}$. Indents were spaced $20 \mu \mathrm{m}$ apart so that the plastic zone of a previous indent did not influence the subsequent indent. The contact radius of each indent at maximum load was less than half of the total film thickness, thus substrate mechanical properties should not drastically impact the measured film properties.

The hardness values of the individual component films, c- TiN ( $300 \mathrm{~nm}$ on $\mathrm{MgO}$ ) and cubic- $\mathrm{Al}_{0.72} \mathrm{Sc}_{0.28} \mathrm{~N}(200 \mathrm{~nm}$ on $20 \mathrm{~nm} \mathrm{TiN} / \mathrm{MgO}$ ), are shown as horizontal dashed lines in Figure 3(a). The reduced modulus is first calculated from the unloading slope of each indentation load-displacement record according to the following equation: ${ }^{25,26}$

$$
S=\frac{d P}{d h}=\frac{2}{\sqrt{ } \pi} E_{r} \sqrt{ } A .
$$

Here, stiffness, $d P / d h$, is experimentally measured from the upper portion of the unloading curve, $A$ is the projected area of the elastic contact, and reduced modulus, $E_{r}$, is defined as

$$
\frac{1}{E_{r}}=\frac{\left(1-\nu^{2}\right)}{E}+\frac{\left(1-\nu_{i}^{2}\right)}{E_{i}}
$$

where $\nu$ and $\mathrm{E}$ are Poisson's ratio and the elastic modulus of the sample, respectively, and $\nu_{\mathrm{i}}$ and $E_{i}$ are Poisson's ratio (0.7) and elastic modulus (1147 GPa) of the diamond indenter, respectively. Hardness is computed by dividing the maximum indentation load, $P_{\max }$, by the projected area, $A$. Represenative load-displacement curves are presented in Figure 3(b).

Single-crystalline c-TiN films grown on $\mathrm{MgO}$ (001) substrates exhibit a hardness of $23 \mathrm{GPa}$ and reduced elastic modulus of $301 \mathrm{GPa}$, consistent with previously published results. ${ }^{9,10}$ The measured hardness of the cubic- $\mathrm{Al}_{0.72} \mathrm{Sc}_{0.28} \mathrm{~N}$ film is $31 \mathrm{GPa}$ with a reduced elastic modulus of $324 \mathrm{GPa}$. The hardness value of the cubic- $\mathrm{Al}_{0.72} \mathrm{Sc}_{0.28} \mathrm{~N}$ alloy thin film is higher than both cubic-ScN and wurtzite-AlN thin films. We cannot accurately use the rule-of-mixtures method to predict the hardness of the $\mathrm{Al}_{0.72} \mathrm{Sc}_{0.28} \mathrm{~N}$ alloy since the
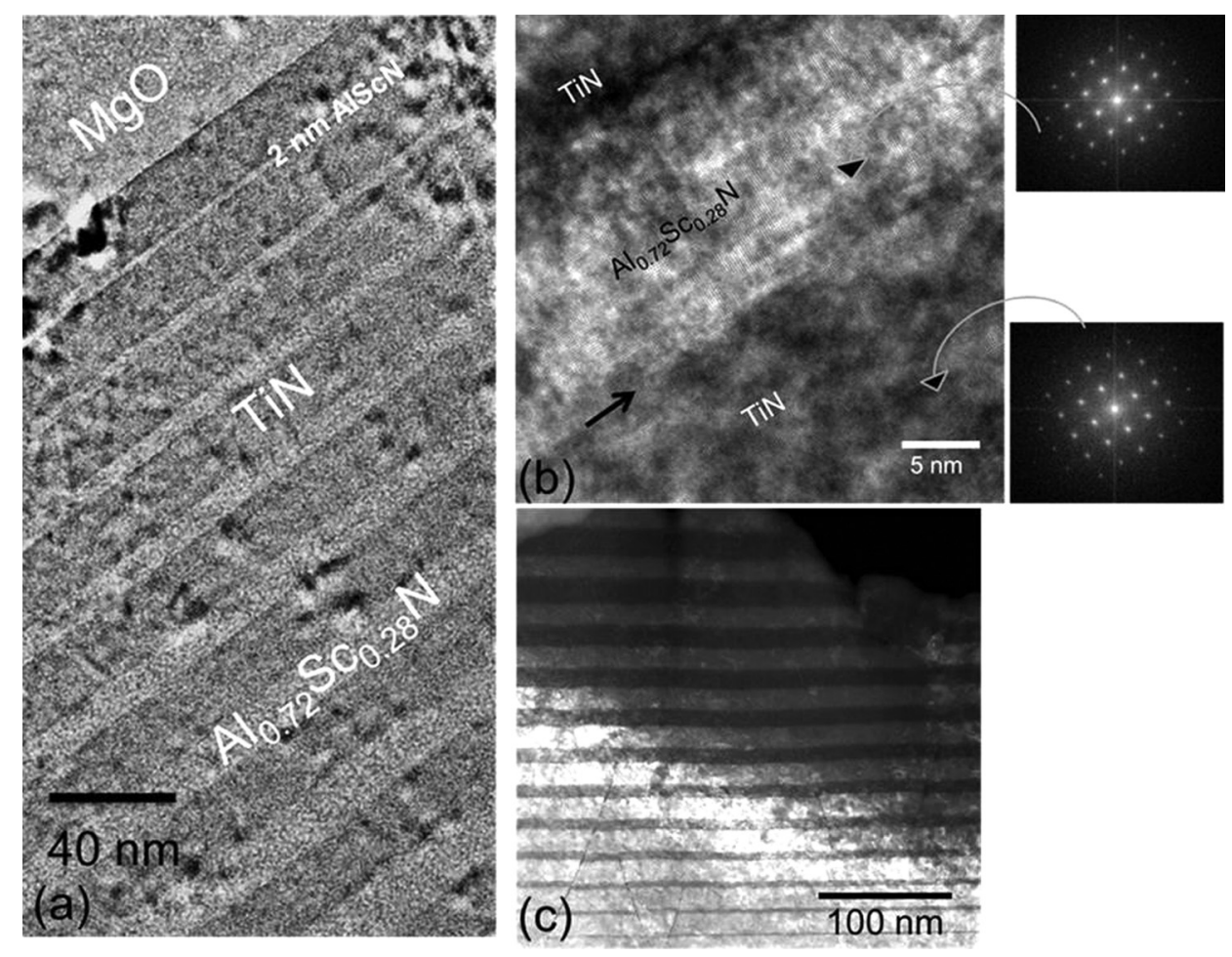

FIG. 2. (a) HRTEM image of a TiN/ $\mathrm{Al}_{0.72} \mathrm{Sc}_{0.28} \mathrm{~N}$ superlattice where the $2 \mathrm{~nm} \mathrm{Al} l_{0.72} \mathrm{Sc}_{0.28} \mathrm{~N}$ layer is clearly visible. The interfaces are sharp and abrupt. The TiN layers are uniform with a thickness of $20 \mathrm{~nm}$. (b) High magnification TEM image of the TiN/ $\mathrm{Al}_{0.72} \mathrm{Sc}_{0.28} \mathrm{~N}$ interface showing cubeon-cube crystal growth. FFT of the TiN and $\mathrm{Al}_{0.72} \mathrm{Sc}_{0.28} \mathrm{~N}$ layers show that both layers are cubic (c) HAADFSTEM image of the superlattice where the TiN layers appear light while the $\mathrm{Al}_{0.72} \mathrm{Sc}_{0.28} \mathrm{~N}$ layers appear dark. The $2 \mathrm{~nm} \mathrm{Al} l_{0.72} \mathrm{Sc}_{0.28} \mathrm{~N}$ layer is also clearly visible in the image. 

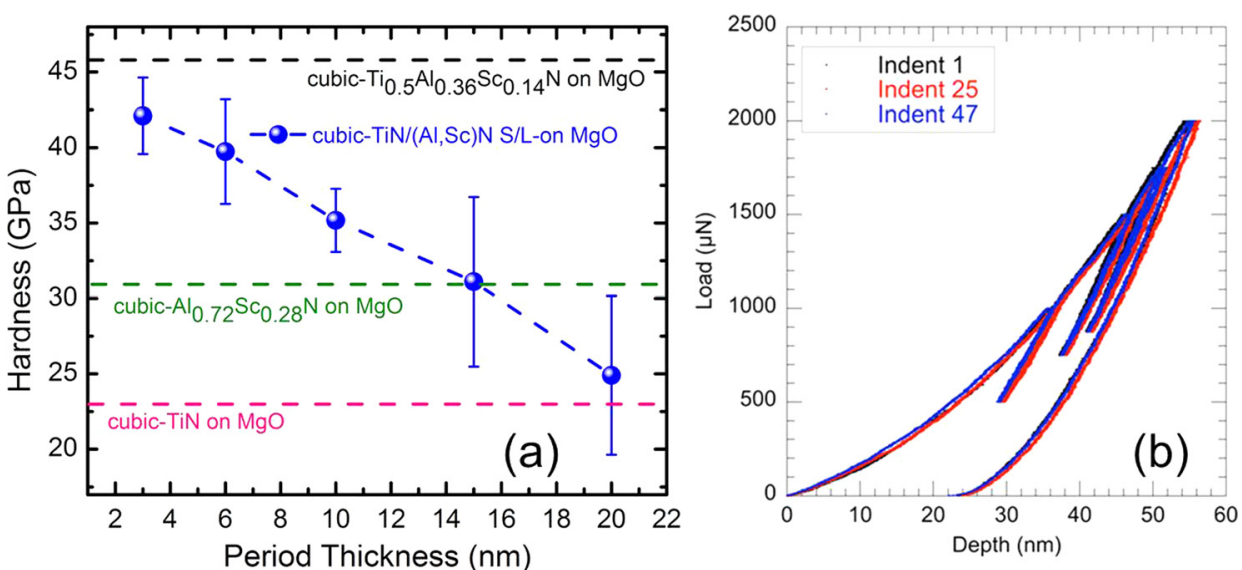

FIG. 3. (a) Superlattice hardness as a function of the superlattice period thickness for superlattices deposited on $\mathrm{MgO}$ (001) substrates. The hardness of superlattices deposited on $\mathrm{MgO}$ increases with decreasing superlattice period. (b) Representative load vs. depth curves during the nano-indentation measurement using the partial-unloading method. hardness of metastable cubic-AlN thin films is unknown. However, given that the hardness of wurtzite-AlN (Ref. 27) is between 11 and $15 \mathrm{GPa}$ and the hardness of cubic-ScN (Ref. 28) is about $21 \mathrm{GPa}$, the measured hardness of the cubic- $\mathrm{Al}_{0.72} \mathrm{Sc}_{0.28} \mathrm{~N}$ alloy is reasonable as other researchers have reported nanoscale system hardness values on the order of 2-3 times greater than the rule-of-mixtures estimates based on the constituent materials. ${ }^{29}$ The hardness enhancement is probably due to the fact that the $\mathrm{Al}_{0.72} \mathrm{Sc}_{0.28} \mathrm{~N}$ alloy is lattice matched with the $\mathrm{TiN} / \mathrm{MgO}$ substrate and grows as an epitaxial single crystal film with a low density of defects and dislocations.

The measured hardness values of the epitaxial singlecrystalline superlattices grown on $\mathrm{MgO}$ (001) substrates are plotted as a function of superlattice period in Figure 3 (hardness values of superlattices grown on $\mathrm{Si}$ (001) and sapphire (0001) substrates are reported in the supplementary material ${ }^{35}$ ). The indentation moduli of all the superlattices grown on $\mathrm{MgO}$ (001) substrates are in the range of $350 \mathrm{GPa} \pm 30 \mathrm{GPa}$ and the moduli do not vary significantly with superlattice period thickness. A slight increase in the modulus with decreasing lattice period may be due to the hardening of the film leading to more bending (i.e., a drumhead) rather than fully plastic indentation throughout the film. ${ }^{30}$

The hardness of the superlattices increases monotonically with decreasing superlattice period thickness. We obtain a maximum hardness of $42 \mathrm{GPa}$ for a $1.5 \mathrm{~nm} / 1.5 \mathrm{~nm}$ $\mathrm{TiN} / \mathrm{Al}_{0.72} \mathrm{Sc}_{0.28} \mathrm{~N}$ superlattice, which is $82 \%$ greater than that of $\mathrm{TiN}$ and $65 \%$ greater than a superlattice hardness of $27 \mathrm{GPa}$ predicted from the rule-of-mixtures. Previous studies on TiN/NbN and TiN/VN superlattices showed that superlattice hardness exhibits a maximum value at a superlattice period of about $8 \mathrm{~nm}$, after which the hardness decreases with decreasing period thickness. The authors of these papers identified intermixing at the superlattice interfaces as a possible reason for such behavior. However, we do not observe any decrease in hardness with decreasing period thickness primarily due to the fact that our superlattices have an interface roughness of about $0.2-0.4 \mathrm{~nm}$, and therefore lack any significant intermixing. The measured hardness of the superlattices is higher than that predicted by the rule-of-mixtures for superlattice periods of $3 \mathrm{~nm}, 6 \mathrm{~nm}, 10 \mathrm{~nm}$, and $15 \mathrm{~nm}$. However, the hardness of the superlattices converges to the hardness of $\mathrm{TiN}(23 \mathrm{GPa})$ when the superlattice period is increased to $20 \mathrm{~nm}$.
Increasing hardness with decreasing period thickness in $\mathrm{TiN} / \mathrm{Al}_{0.72} \mathrm{Sc}_{0.28} \mathrm{~N}$ superlattices follows the trend observed in nanoscale metallic multilayers of $\mathrm{Cu}$ and $\mathrm{Ni}$ as described by Misra et al. ${ }^{31}$ The authors report a hardness increase of nearly three times when the period thickness of a $\mathrm{Cu}-\mathrm{Ni}$ system decreases from $200 \mathrm{~nm}$ to $10 \mathrm{~nm}$; this strength enhancement is consistent with the breakdown of Hall-Petch behavior in nanoscale materials and suggests that deformation behavior is no longer controlled by dislocation pile-ups. The period thicknesses and similar crystallography of the $\mathrm{TiN} / \mathrm{Al}_{0.72} \mathrm{Sc}_{0.28} \mathrm{~N}$ superlattices investigated in this work suggest that single-dislocation-based strengthening mechanisms likely control deformation in this system.

During the initial stages of superlattice plastic deformation, glide dislocations are confined to slip in a single layer. A dislocation loop nucleated within a layer will glide by the Orowan bowing mechanism parallel to the interface, leaving behind misfit dislocations along the interface as it moves. When a layer yields plastically, load is transferred to the next elastically deforming layer; full plasticity in the composite occurs once sufficient load is transferred so as to allow slip transmission across the interface and yielding of the adjacent layer. The strength of multilayer systems scales ${ }^{32}$ with $\ln (h) / h$, where $h$ is the period thickness. As period thickness decreases, the Orowan stress confined to a single layer increases, leading to an overall increase in the hardness of the superlattice.

Coherency stresses resulting from lattice parameter mismatch $^{33,34}$ and Koehler images forces resulting from shear modulus mismatch ${ }^{14}$ have been invoked to explain strength increases in certain coherent nanoscale metallic multilayers. However, below a critical thickness for coherency loss, the coherency stress is typically independent of layer thickness. ${ }^{33}$ Additionally, in the current superlattice system, TiN and $\mathrm{Al}_{0.72} \mathrm{Sc}_{0.28} \mathrm{~N}$ are nearly lattice matched, reducing the likelihood of misfit dislocations at the interface. Thus, it is unlikely that coherency stress effects contribute significantly to the observed hardening. Furthermore, the shear moduli of the TiN and $\mathrm{Al}_{0.72} \mathrm{Sc}_{0.28} \mathrm{~N}$ layers do not differ greatly; it is unlikely that substantial strengthening is derived from the development of Koehler image forces between layers. Therefore, hardening of TiN/ $\mathrm{Al}_{0.72} \mathrm{Sc}_{0.28} \mathrm{~N}$ superlattices as period thickness decreases is likely best described by the Orowan bowing mechanism of the confined layer slip model.

The hardness of a $\mathrm{Ti}_{0.5} \mathrm{Al}_{0.36} \mathrm{Sc}_{0.14} \mathrm{~N}$ alloy thin film (Fig. 3(a)) was also measured since it represents the equivalent 
alloy of the TiN/Al $\mathrm{Al}_{0.72} \mathrm{Sc}_{0.28} \mathrm{~N}$ superlattices. Surprisingly, the hardness of this alloy is about $46 \mathrm{GPa}$, which is higher than the maximum hardness exhibited by any of the superlattices. The elastic modulus of this alloy sample is also high $(\approx 410 \mathrm{GPa})$. X-ray analysis indicates that the crystal quality of the $\mathrm{Ti}_{0.5} \mathrm{Al}_{0.36} \mathrm{Sc}_{0.14} \mathrm{~N}$ alloy thin film is better than that of the superlattices, which is manifested by a smaller rocking curve FWHM value. Therefore, the high hardness could be due to an extremely low density of defects and dislocations; the strengthening mechanism in this novel crystalline alloy with high impurity content but low line or area defects is likely different than the Orowan mechanism that is the suspected hardening method in the multilayer. Further, microstructural analysis is needed to help explain the details of high hardness of this alloy film. Nevertheless, an alloy film with hardness higher than a superlattice of the same constituent materials is desirable as an industrial hard coating due to the alloy's enhanced mechanical properties, the ease of deposition for alloys compared to superlattices, and the enhanced long-term thermal stability compared to superlattices whose layered structure may break down via diffusion mechanisms.

In conclusion, an epitaxial $\mathrm{Ti}_{0.5} \mathrm{Al}_{0.36} \mathrm{Sc}_{0.14} \mathrm{~N}$ alloy thin film and epitaxial rocksalt-TiN/Al $\mathrm{Al}_{0.72} \mathrm{Sc}_{0.28} \mathrm{~N}$ superlattices are developed that show significant hardness enhancement compared to TiN and industrial-based TiAlN hard coatings. Incorporation of scandium increases the critical thickness of the metastable cubic- $\mathrm{Al}_{0.72} \mathrm{Sc}_{0.28} \mathrm{~N}$ phase in TiN/ $\mathrm{Al}_{0.72} \mathrm{Sc}_{0.28} \mathrm{~N}$ superlattices and results in higher hardness values compared with TiN/AlN superlattices. The hardness of the superlattices increases monotonically with decreasing superlattice period and the equivalent $\mathrm{Ti}_{0.5} \mathrm{Al}_{0.36} \mathrm{Sc}_{0.14} \mathrm{~N}$ alloy thin film exhibits the highest hardness value. The TiN/ $\mathrm{Al}_{0.72} \mathrm{Sc}_{0.28} \mathrm{~N}$ superlattices grow with 002-orientation on $\mathrm{MgO}$ (001) substrates with sharp interfaces, and are stable in the cubic phase at $1050^{\circ} \mathrm{C}$ for $4 \mathrm{~h}$, after which the cubic $\mathrm{Al}_{0.72} \mathrm{Sc}_{0.28} \mathrm{~N}$ layers begin to transform into the thermodynamically stable wurtzite phase. The high hardness and excellent thermal stability make the $\mathrm{Ti}_{0.5} \mathrm{Al}_{0.36} \mathrm{Sc}_{0.14} \mathrm{~N}$ alloy thin films and $\mathrm{TiN} / \mathrm{Al}_{0.72} \mathrm{Sc}_{0.28} \mathrm{~N}$ superlattices attractive hard-coating candidates for cutting tool applications. The $\mathrm{Ti}_{0.5} \mathrm{Al}_{0.36} \mathrm{Sc}_{0.14} \mathrm{~N}$ alloy is particularly attractive and deserves further study using industrial-relevant tooling substrates such as cemented carbide.

B.S. and T.D.S. acknowledge financial support by the National Science Foundation and U.S. Department of Energy (CBET-1048616). S.K.L. acknowledges financial support by the Department of Energy National Nuclear Security Administration Stewardship Science Graduate Fellowship Program under Grant No. DE-FC52-08NA28752. J.L.S. and J.B. acknowledge financial support from Linköping University and the Swedish Research Council (the RÅ Frame Program (No. 2011-6505) and the Linnaeus Grant (No. LiLi-NFM)). Synchrotron measurements were conducted at the P07 High Energy Materials Science beamline at PETRA
III, DESY (Hamburg, Germany). Our special thanks to Norbert Schell, P07 beamline scientist, for assistance with synchrotron measurements.

${ }^{1}$ W. D. Callister, Jr., Materials Science and Engineering: An Introduction, 7th ed. (John Wiley and Sons, Inc., 2007).

${ }^{2}$ A. C. Fischer-Cripps, Nanoindentation, 2nd ed. (Springer, 2004).

${ }^{3}$ R. B. Kaner, J. J. Gilman, and S. H. Tolbert, Science 308, 1268 (2005).

${ }^{4}$ A. M. Korsunsky, M. R. McGurk, S. J. Bull, and T. F. Page, Surf. Coat. Technol. 99, 171-183 (1998).

${ }^{5}$ J. Musil, Surf. Coat. Technol. 125, 322-330 (2000).

${ }^{6}$ S. Stoupin and Y. V. Shvyd'ko, Phys. Rev. Lett. 104, 085901 (2010).

${ }^{7}$ B. Saha, J. Acharya, T. D. Sands, and U. V. Waghmare, J. Appl. Phys. 107, 033715 (2010)

${ }^{8}$ Transition Metal Carbides and Nitrides, edited by L. Toth (Academic Press, 1971).

${ }^{9}$ J. E. Sundgren, Thin Solid Films 128, 21-44 (1985).

${ }^{10}$ S. Zhang and Z. Weiguang, J. Mater. Process. Technol. 39, 165-177 (1993).

${ }^{11}$ N. C. Saha and H. G. Tompkins, J. Appl. Phys. 72, 3072-3079 (1992).

${ }^{12}$ S. PalDey and S. C. Deevi, Mater. Sci. Eng., A 342, 58-79 (2003).

${ }^{13}$ P. H. Mayrhofer, A. Hörling, L. Karlsson, J. Sjölén, T. Larsson, C. Mitterer, and L. Hultman, Appl. Phys. Lett. 83, 2049 (2003).

${ }^{14}$ J. S. Koehler, Phys. Rev. B 2, 547 (1970).

${ }^{15} \mathrm{H}$. Ljungcrantz, C. Engstrom, L. Hultman, M. Olsson, X. Chu, M. S. Wong, and W. D. Sproul, J. Vac. Sci. Technol., A 16, 3104-3113 (1998).

${ }^{16}$ U. Helmersson, S. Todorova, S. A. Barnett, J.-E. Sundgren, L. Co Markert, and J. E. Greene, J. Appl. Phys. 62, 481-484 (1987).

${ }^{17}$ H. Barshilia, A. Jain, and K. S. Rajam, Vacuum 72, 241-248 (2003).

${ }^{18}$ D. Kim, T.-Y. Seong, and Y.-J. Baik, Surf. Coat. Technol. 153, 79-83 (2002).

${ }^{19}$ M. Setoyama, M. Irie, H. Ohara, M. Tsujioka, Y. Takeda, T. Nomura, and N. Kitagawa, Thin Solid Films 341, 126-131 (1999).

${ }^{20}$ M. Wong, G.-Y. Hsiao, and S.-Y. Yang, Surf. Coat. Technol. 133, $160-165$ (2000).

${ }^{21}$ A. Madan, I. W. Kim, S. C. Cheng, P. Yashar, V. P. Dravid, and S. A. Barnett, Phys. Rev. Lett. 78, 1743 (1997).

${ }^{22}$ B. Saha, S. Saber, G. V. Naik, A. Boltasseva, E. Stach, E. Kvam, and T. D. Sands, "Development of epitaxial $\mathrm{Al}_{x} \mathrm{Sc}_{1-} x \mathrm{~N}$ for artificially structured metal/semiconductor superlattice metamaterials," Phys. Status Solidi B (published online).

${ }^{23}$ G. V. Naik, B. Saha, J. Liu, S. M. Saber, E. Stach, J. M. Irudararaj, T. D. Sands, V. M. Shalaev, and A. Boltasseva, Proc. Natl. Acad. Sci. U.S.A. 111, 7546 (2014).

${ }^{24}$ B. Saha, G. V. Naik, S. Saber, C. Akatay, E. Stach, V. Shalaev, A. Boltasseva, and T. D. Sands, Phys. Rev. B 90, 125420 (2014).

${ }^{25}$ C. Hoglund, B. Alling, J. Birch, M. Beckers, P. O. Å. Persson, C. Baehtz, Z. Czigany, J. Jensen, and L. Hultman, Phys. Rev. B 81, 224101 (2010).

${ }^{26}$ W. C. Oliver and G. M. Pharr, J. Mater. Res. 7, 1564-1583 (1992).

${ }^{27}$ I. C. Oliveira, K. G. Grigorov, H. S. Maciel, M. Massi, and C. Otani, Vacuum 75, 331-338 (2004).

${ }^{28}$ D. Gall, I. Petrov, N. Hellgren, L. Hultman, J. E. Sundgren, and J. E. Greene, J. Appl. Phys. 84, 6034 (1998).

${ }^{29}$ R. R. Oberle and R. C. Cammarata, Scr. Metall. Mater. 32, 583-588 (1995); H. Geisler, K. O. Schweitz, J. Chevallier, J. B $\oslash$ ttige, and K. Samwer, Philos. Mag. A 79, 485-500 (1999).

${ }^{30}$ W. W. Gerberich, A. Strojny, K. Yoder, and L.-S. Cheng, J. Mater. Res. 14(6), 2210-2218 (1999).

${ }^{31}$ A. Misra, J. P. Hirth, and H. Kung, Philos. Mag. A 82, 2935-2951 (2002).

${ }^{32}$ J. D. Embury and J. P. Hirth, Acta Metall. Mater. 42, 2051-2056 (1994); W. D. Nix, J. R. Greer, G. Feng, and E. T. Lilleodden, Thin Solid Films $\mathbf{5 1 5}, 3152-3157$ (2007).

${ }^{33}$ R. G. Hoagland, T. E. Mitchell, J. P. Hirth, and H. Kung, Philos. Mag. A 82, 643-664 (2002).

${ }^{34}$ W. D. Sproul, Science 273, 889-892 (1996).

${ }^{35}$ See supplementary material at http://dx.doi.org/10.1063/1.4898067 for nano-indentation studies on superlattice and thin film samples grown on $\mathrm{Si}$ and sapphire substrates and growth, characterization techniques. 